\title{
A Mente Molecularizada e a Busca da Demência Incipiente ${ }^{1}$
}

MARGARETH LOCK*

\section{RESUMO}

A autora apresenta uma visão crítica do determinismo genético predominante em parte da pesquisa genética, a partir de uma revisão de seus principais marcos históricos, recorrendo a autores como Kay e Lewontin, entre outros. A partir desta delimitação, aborda a discussão em torno da possibilidade de um diagnóstico precoce da doença de Alzheimer (DA), incluindo-se tentativas de identificar possíveis marcadores de risco para a mesma, a discussão das próprias dificuldades diagnósticas e mesmo taxonômicas da DA, em particular da forma denominada de início tardio (late onset). A autora enfatiza o quanto as várias teorias causais vigentes (relevantes para a idéia de diagnóstico precoce) desvalorizam ou mesmo omitem a participação de fatores sociais no desencadeamento da DA. A seguir, destaca os vários e conflitantes achados sobre possíveis marcadores genéticos de risco para a DA, que apesar de sua precariedade ainda assim levam à produção de testes para sua detecção. Por fim, a autora examina em detalhes o projeto REVEAL, do National Institutes of Health (NIH, órgão governamental norte-americano), ora em curso e que busca identificar o gene APOE na população geral americana. $\mathrm{O}$ artigo se encerra com uma descrição das repercussões subjetivas nos indivíduos que participaram desse teste.

Palavras-chave: Doença de Alzheimer; Antropologia médica; genética; estudos sobre ciência.

Recebido em: 11/10/2005.

Aprovado em: 06/12/2005. 


\section{Introdução}

A visão molecular de vida que predominou na segunda metade do século $\mathrm{XX}$, culminando recentemente no mapeamento do genoma humano, está fundamentada numa biologia mecanicista cujo objetivo principal é permitir a engenharia de corpos e mentes (KAY, 1993, p. 17). Essa forma particular de molecularização é determinística, e assume que o conhecimento sobre genes específicos permite fazer previsões confiáveis sobre a ocorrência de doenças. Como parte desse esforço, as inovações tecnológicas ocorridas ao longo dos últimos vinte anos facilitaram a testagem genética e o rastreamento de indivíduos, o que teve tanto consequiências negativas quanto positivas (DUSTER, 1990; KITCHER, 1996). Entretanto, essa forma particular de biologia molecular, embora válida para desordens genética simples, apresenta sinais de declínio. Teoria e pesquisa sobre genes de suscetibilidade ${ }^{2}$ para doenças e comportamentos complexos realizaram mudança fundamental na biologia molecular, na ordem da mudança de paradigma, com grandes conseqüências potenciais para o tratamento clínico de todos os tipos, incluindo a testagem genética de indivíduos.

No mapeamento do genoma humano, os cientistas envolvidos deixaram de lado 98\% do DNA que haviam isolado, o qual denominaram de "lixo", porque este não se adequava à sua idéia de como funcionaria o "projeto técnico" da vida. Desde o anúncio, no início de 2001, de que o Projeto Genoma Humano estava mais ou menos completo, as coisas mudaram bastante, e o DNA lixo deixado de lado para que os cientistas se detivessem na tarefa de mapear apenas os genes que codificam as proteínas, não podem mais ser ignorados. A revista Scientific American publicou recentemente:

\footnotetext{
"new evidence [...] contradicts conventional notions that genes [...] are the sole mainspring of hereditary and the complete blueprint for all life. Much as dark matter influences the fate of galaxies, dark parts of the genome exert control over the development and the distinctive traits of all organisms, from bacteria to humans [...] some scientists now suspect that much of what makes one person, and one species, different from the next are variations in the gems hidden within our 'junk' DNA" (GIBBS, 2003, p. 48).
}

Esse lixo é composto em grande parte de $\mathrm{RNA}^{3}$, que não codifica a produção de proteína, mas mesmo assim está implicado na expressão e regulação do gene, e agora deve ser esquadrinhado (EDDY, 2001; MATTICK, 
2003 e 2004). O resultado é que, quase que da noite para o dia, entramos numa era em que as partes "sombrias" do genoma estão começando a se iluminar.

Acredita-se que as atividades do RNA não-codificável (ncRNA) compreendam o sistema regulador mais abrangente dos organismos complexos; ele cria a "arquitetura" dos organismos, sem a qual o caos reinaria (MATTICK, 2003). Foi mostrado que o ncRNA afeta profundamente os processos que ocorrem durante o desenvolvimento, incluindo a manutenção de células-tronco, proliferação celular, apoptose (morte celular programada), o início do câncer e outras enfermidades complexas (PETRONIS, 2001). Como conseqüência, os interesses da pesquisa em biologia molecular não estão mais confinados ao mapeamento de estruturas, mas se voltaram para a decifração dos mecanismos de funcionamento de células e órgãos ao longo do tempo. O mais importante, nesse esforço, é compreender a regulação genética - sobretudo como, e em que circunstância, os genes são "ligados" e " desligados"4. Numa ciência que vem se desenvolvendo rapidamente, conhecida como epigenética, a complexidade organizada é reconhecida e as atividades celulares, mais do que apenas as dos genes, são o principal foco de investigação, embora os efeitos das variáveis evolutivas, históricas e ambientais da atividade celular, os processos de desenvolvimento, saúde e doença sejam reconhecidos.

Esse conhecimento emergente implodiu o principal dogma em que se baseava a genética molecular. As metáforas associadas ao mapeamento do Genoma Humano - o Livro da Vida, o Código dos Códigos, o Santo Graal e outros - estão completamente fora de moda. O resultado é que aquele fetichismo genético nunca abraçado com entusiasmo por todos os cientistas envolvidos (ver BERG, 1991 e DAVIS, 1990, para citar apenas dois) agora perde importância para muitos, senão a maioria, dos expertos. O DNA não é afinal a planta básica do organismo. O gene perdeu o lugar de "parte átomo do físico e parte alma de Platão" (FOX KELLER, 2000a, p. 277), e não pode mais desempenhar o papel de principal força animadora da vida humana. Ironicamente, as mesmas tecnologias de molecularização que permitiram a manipulação sistemática do DNA agora estão desfazendo o dogma genótipo/fenótipo que conduziu a abordagem reducionista da genética dominante nos últimos 50 anos. A atual "desordem na definição do gene" (FOX KELLER, 2000a, p. 274; cf. RHEINBERGER, 1995) foi trazida pelos achados do Projeto Genoma Humano e "os genes lembraram, pelo menos a alguns biólogos, do organismo, apontando para sua peculiaridade biológica, distinta de suas propriedades estritamente bioquímicas". Em outras palavras, “devemos afirmar que o 'organismo' foi 
retirado de sua antiga submissão e levado à entidade material" (FOX KELLER, 2000a, p. 275).

Com a célula no centro das atenções, as interações gene/gene, gene/ proteína e gene/ambiente não podem ser ignoradas, e os caminhos biológicos não são mais considerados necessariamente lineares ou unidirecionais. Abriuse um espaço entre o genótipo e o fenótipo que foi em parte reconhecido cem anos atrás, mas convenientemente deixado de lado. Sobre esse desenvolvimento, o biólogo Richard Lewontin comenta:

"Unlike planets, which are extremely large, or electrons, which are extremely small and internally homogenous, living organisms are intermediate in size and internally heterogeneous. They are composed of a number of parts with different properties that are in dynamic interaction with one another and the parts are, in turn, composed of yet smaller parts with their own interactions and properties. Moreover, they change their shapes and properties during their lifetimes, developing from a fertilized egg to a mature adult, ending finally sans teeth, sans hair, sans everything. In short: organisms are a changing nexus of a large number of weakly determining interacting forces" (LEWONTIN, 2003, p. 39).

Lewontin especula se a biologia é inevitavelmente uma história de "cada terra tem seu uso", uma coleção de descrições delicadamente detalhadas de diversas formas e funções até o nível molecular, ou dessa "confusão estrondosa, alvoroçada" pode um biólogo deduzir algumas reivindicações gerais que estão livres das sórdidas particularidades de cada caso? Não as leis, com certeza, mas talvez pelo menos alguma característica largamente compartilhada? Lewontin concorda com Fox Keller (2002), para quem a história e a epistemologia contestam tanto um quanto outro, na medida em que dizem respeito ao sentido da vida; todos os nossos modelos, metáforas e máquinas, apesar de muito terem contribuído para nosso entendimento, não oferecem unidade nem completude. Ao contrário - lidar com a complexidade é a ordem do dia, embora muitos problemas renitentes continuem a ser cuidadosamente evitados e, o mais desconcertante de tudo, muito do que se considerou estabelecido quanto à função dos genes agora tem que ser revisto.

Entrevista realizada com o diretor financeiro da Perlegen Sciences, parcialmente publicada em Genetic Engineering News (DUTTON, 2003), esclarece que, com base nas revelações sobre complexidade, a genômica mo- 
lecular se encontra num impasse: "o sonho é identificar os marcadores genéticos para doenças através do seqüenciamento genômico de centenas de milhares de pessoas com ou sem determinada doença. Ainda assim, isso não é prático". A mesma revista observa que a genômica e a proteômica até agora não resultaram em melhorias no diagnóstico ou na terapêutica (cf. ANGELL, 2004), e um funcionário da Curagen é citado como tendo afirmado: "Ano passado foi o pior da década, em termos do número de drogas novas aprovadas pelo FDA. Apenas uma delas atua especificamente contra um alvo recentemente identificado do genoma humano. A indústria farmacêutica está paralisada". Outro entrevistado acrescenta: "mesmo se eu pudesse seqüenciar seu próprio genoma, não haveria muito o que você pudesse fazer com a informação sobre a sequiência bruta hoje em dia".

\section{Reducionismo Agressivo}

Uma revisão crítica da história da genética desde o final do século XIX (ver FOX KELLER, 2000b; JAN SAPP 1983) mostra como, por mais de cem anos, paramos na etapa da super-simplicação. As batalhas disciplinares de então eram, como sempre, lutas pelo poder e pela autoridade, nas quais a criação de uma distinção genótipo/fenótipo - uma parte dividida entre a estrutura e sua expressão - superava idéias antigas sobre herança - chamadas de "conceito de transmissão de hereditariedade", segundo o qual se supunha que as qualidades e comportamentos pessoais eram passados de geração a geração. Kerr et al. (1998) e Lock et al. (no prelo) mostraram que o "conceito de transmissão de hereditariedade" continua a ser utilizado por muitos, talvez pela maioria das pessoas, em sua vida cotidiana, mas a adoção da distinção genótipo/fenótipo na emergente profissão do campo da genética eliminou essa idéia associativa entre os estudiosos, e balançou o pêndulo para muito longe, na direção do determinismo genético. No início do século XX, a genética foi comparada, por seu fundador, o cientista dinamarquês Wilhelm Johannsen, à "dura" ciência da química (1923). E o desejo expresso mais tarde por H. E. Armstrong (1931, p. 238), que escreveu que "um dia, talvez, a biografia seja escrita quase nos termos da química estrutural, e a doutrina da descendência afirmada nos termos das permutações e combinações produzidas entre os genes". Qualquer outra ordem de explicação foi considerada supérflua.

Daniel Dennet argumenta que os cientistas exibem um "reducionismo agressivo" quando, "preocupados em explicar muita coisa muito rapidamente, 
eles subestimam a complexidade, tentando pular camadas ou níveis de teoria inteiros na sua ânsia de manter tudo seguramente fixado à base" (1995, p. 82). As sementes foram plantadas para esse tipo de reducionismo, uma vez que a distinção genótipo/fenótipo se tornou um dogma, uma posição que mais tarde seria estabelecida, no famoso texto de Watson e Crick, "A estrutura do DNA" (1953), que fundamentou o dogma central da nova biologia molecular.

Como se sabe, Watson e Crick provaram a existência de um fluxo de informação unidirecional do DNA ao RNA, para a proteína e o fenótipo, consolidando assim o poder do gene. Bastante influenciada, a partir dos anos 1950, pela tecnologia computacional e pelo deslumbramento com as ciências da informação, a idéia do genoma como um modelo informacional avançou, reificando o próprio gene e transformando todo o resto em trivialidade. Qualquer possível contribuição para o fenótipo feita pelo ambiente interno do organismo, sobretudo aquele das células individuais, e a resposta do organismo como um todo às mudanças ambientais foram abandonadas, tais como destroços de um naufrágio (FOX KELLER, 2002).

Gabriel Gudding observa que o desaparecimento do corpo na genética molecular na última década está associado às novas tecnologias que permitem a rápida análise do DNA e viabilizam a recolocação maciça da agência e da moralidade no gene (1996). Ele nos lembra de como a crescente evidência do DNA é usada como a marca irrefutável da identidade, seja na sala de um tribunal, como evidência forense, ou para determinar se uma atleta é realmente o que ela afirma ser. Nossas biografias são, pelo menos em parte, escritas em termos da química estrutural, e a busca pela seqüêencia de milhares de genomas - humanos, animais e botânicos - tem sido levada a cabo rapidamente, embora muitas vezes os achados que surgem não são os previstos e causam surpresa tanto em termos da extensão dos genomas quanto das extensas correspondências do DNA entre eles.

Apesar do falatório associado ao seqüenciamento do genoma humano, com suas metáforas deslocadas sobre o mapeamento e a revelação do Segredo da Vida, mesmo antes do início do seqüenciamento a maioria dos cientistas envolvidos sabia que o mapeamento era apenas uma pequena parte da história. Quando o genoma humano se tornou mais ou menos conhecido, afirmava-se que o mapa resultante se parecia mais com uma lista de partes que compunham um Boeing 747: não se tinha a menor idéia de como juntar essas partes e noção alguma sobre princípios de aeronáutica. O mapa representa tão somente uma 
redução da vida a uma simples estrutura, não dando qualquer noção sobre suas funções.

\section{Reduzindo a Complexidade}

Na prática, para a maior parte dos pesquisadores na área de ciência básica, a elucidação da complexidade associada à função consiste num esforço para esclarecer o que acontece no "espaço" hipotético entre o genótipo e o fenótipo. A maioria dos pesquisadores que trabalham com genética molecular reconhece que o ambiente e as variáveis sociais desempenham papel crucial na modificação dos organismos; mesmo assim, essas variáveis são isoladas na preferência por uma abordagem decididamente preocupada com interações internas ao corpo material. Logo, a maioria das modelagens continua a ser reducionista e, assim, supersimplificada, mas a caracterização dessa pesquisa como integrante do determinismo genético não mais se aplica.

Na psiquiatria, por exemplo, Irving Gottesman sugere que modelos de desordens genéticas complexas "predizem um balé interativamente coreografado ao longo do tempo entre genótipo, ambiente e fatores, dando origem a um fenótipo particular" (1994). Há trinta anos, Gottesman e Shields, ao investigarem a esquizofrenia, inspirados por publicações sobre a biologia dos insetos, formularam um conceito de "endofenótipos" que eles descreveram como "fenótipos internos" descobertos através de um "teste bioquímico ou exame microscópio". Eles sustentam que os endofenótipos oferecem os meios para identificar os traços ou facetas "rio abaixo" dos fenótipos clínicos, assim como as conseqüências "rio acima" dos efeitos genéticos (1972). Pouco se fez com esse conceito até recentemente, mas referências a ele na genética psiquiátrica agora são comuns, e ele está começando a aparecer em algumas publicações das outras disciplinas de ciências humanas. Gottesman admite que termos similares de uso corrente, "fenótipo intermediário", "marcador biológico" ou "biomarcador", "traço subclínico" e "marcador de vulnerabilidade" são basicamente sinônimos do conceito de endofenótipo, mas ele quer limitar o uso deste último aos casos específicos nos quais os indicadores de hereditariedade são preenchidos. Por outro lado, argumenta, os biomarcadores podem ser produtos de efeitos ambientais, epigenéticos ou multifatoriais.

Essa mudança na ênfase constitui uma mudança epistemológica que se afasta do determinismo, e com ela surgiu a esperança da redefinição de 
categorias diagnósticas. Estas são capazes de classificar, por exemplo, a esquizofrenia, a desordem bipolar e outras, em subtipos claramente diferenciados e produzir medicações farmacogenéticas sob encomenda para esses subtipos. Mas, como mencionado acima, até agora não houve produtos.

Na próxima seção abordaremos a condição da demência, na doença de Alzheimer em especial, para ilustrar como a nova abordagem epigenética para a doença complexa está sendo desgastada na pesquisa em ciência básica. $\mathrm{Na}$ última seção, iremos apresentar alguns dados etnográficos que nos dão idéia de alguns dos efeitos sociais associados à testagem para susceptibilidade genética.

\section{Em Busca da Demência Prodrômica}

A cobertura da mídia sobre a morte de Ronald Reagan em junho de 2004 incluía uma matéria de jornal cujo título era: "O sorriso que era sua marca registrada já era o primeiro sinal da doença de Alzheimer?”. O autor, um médico, sugeria ser possível que a história de vida de Reagan e seus padrões emocionais possam ter preparado o terreno para a doença que mais tarde lhe roubou o raciocínio, a fala e o movimento. Ele afirmou: "Fortes evidências sugerem que a falta de uma plena capacidade emocional é fator de risco para o desenvolvimento da doença de Alzheimer", e lembra que Reagan tinha um "pai alcoólatra e irresponsável, e uma mãe emocionalmente ausente" (MATÉ, 2004). Essa informação foi associada, no mesmo artigo, a achados do famoso Nun's Study, do qual participaram 678 freiras católicas que pertenciam à ordem denominada The School Sisters of Notre Dame, espalhada por sete regiões dos EUA. Textos escritos por essas freiras quando eram jovens, sobre os motivos que as levaram a querer entrar para a Ordem, cuidadosamente guardados durante décadas, foram comparados com avaliações neuropsiquiátricas realizadas após os 75 anos de idade das freiras, e depois associadas a achados das autópsias após a morte delas (todas as freiras concordaram, ao entrarem no projeto, a doar o cérebro para autópsia). Argumenta-se, com base nesse estudo, que os indivíduos que possuíam pensamento imaginativo e complexo na juventude (isto é, apresentavam "alta densidade ideativa", na linguagem dos pesquisadores), provavelmente não sofreriam do mal de Alzheimer na velhice (SNOWDON, 2001). Esse achado não foi relacionado ao número de anos de educação formal, e descartado à medida que se acumulavam: 90\% das freiras cujos cérebros apresentavam danos extensos tinham "baixa densidade ideativa" aos vinte anos 
de idade. A pesquisa deu grande impulso ao que mais tarde ficou conhecido como a hipótese da "reserva cerebral" - reserva que começa a se estabelecer ainda in utero, e tem avançado muito, quando se teoriza sobre quem corre risco de adquirir a doença de Alzheimer (DA).

De maior interesse ainda foi o achado segundo o qual uma pequena proporção de freiras que colaboraram com a bateria de testes neuropsicológicos apresentou, no resultado da autópsia, extensos sinais de placas e emaranhados, considerados, desde o tempo de Alois Alzheimer, os marcadores patológicos da doença. Pesquisa recente, incluindo um projeto no qual os cérebros de pessoas centenárias foram autopsiados, apresentou resultados similarmente contraintuitivos (SILVER et al., 2001). Inversamente, também se reconhece que uns poucos indivíduos cujos cérebros autopsiados apresentaram número relativamente pequeno de alterações anatômicas exibiram todos os sinais comportamentais da demência enquanto viviam (SWARTZ et al., 1999).

Aumentando a confusão, hoje está evidente que as demências, talvez sem exceção, vêm em "formas variadas", de modo que a demência cérebrovascular em geral se apresenta junto com uma DA tardia; por outro lado, a DA tardia pode se misturar à demência fronto-temporal que causa alucinações. Contudo, existem outras permutações e combinações entre as "desordens demenciais", um grupo taxonômico que inclui a doença de Creutzfeldt-Jakob. Potencialmente, ninguém afirmaria hoje que a demência seja um mito, um exemplar de construção social, como alguns expertos argumentaram em passado recente (STAFFORD, 1991); nem as placas e os emaranhados são fantasia, mas a instalação tardia da DA talvez seja um ficção conveniente; dentre os profissionais médicos ela é implicitamente reconhecida como um alvo mutável, instável, que os expertos concordam que deve ser mencionado nos prontuários como "provável doença de Alzheimer" até que uma autópsia, se feita, confirme o diagnóstico (embora, como dito acima, mesmo as autópsias não constituam necessariamente uma evidência). Após anos tentando melhorar tanto a sensibilidade quanto a especificidade dos diagnósticos de DA, mesmo nos centros médicos acadêmicos, sua acurácia varia de $63 \%$ a $90 \%$. Por enquanto, pelo menos um clínico/pesquisador escreveu um artigo intitulado "O fim da doença de Alzheimer", no qual ele especula que na era pós-genômica iremos abolir completamente esse rótulo inoportuno (WHITEHOUSE, 2001) - uma possibilidade que é combatida por razões óbvias pela International Alzheimer Society e por suas várias sedes. 
Esses paradoxos imediatamente suscitam a pergunta sobre o status ontológico da DA tardia - o que é isso e onde exatamente isso reside? As alterações comportamentais diagnosticadas com base em testes psicológicos, ou a patologia anatômica demonstrada pela autópsia constituem a doença? E qual é a exata implicação dos genes? Muitos cientistas e clínicos envolvidos são sensíveis a esse enigma taxonômico, embora poucos, é claro, estejam claramente preocupados com a ontologia.

\section{Definindo a Doença de Alzheimer}

A Divisão de População das Nações Unidas estima que o número de pessoas no mundo com 60 anos de idade ou mais ultrapassou 635 milhões em 2002. Em meados do século deverão ser cerca de dois bilhões de pessoas, considerando-se que a fome e as doenças contagiosas não aumentem mais do que os índices atuais. Isso significa que uma em cada três pessoas, ou mesmo uma em cada duas, se a crise da AIDS continuar no patamar atual, terá mais de 60 anos de idade; e os idosos mais velhos representam o grupo que mais aumenta dentre os de terceira idade. Os governos estão assustados, e a indústria farmacêutica está ávida por avanços no que hoje é descrito como "pandemia de envelhecimento". O medo de ser inundado por idosos com demência significa que há dinheiro disponível para pesquisa; ao mesmo tempo, tecnologias genômicas se tornaram cada vez mais eficientes, e o conhecimento sobre os mecanismos moleculares da DA avançou. Ainda assim, atualmente, não existem nem grandes medidas preventivas nem tratamentos que façam pouco mais do que melhorar por alguns meses o estado de alguns pacientes - e esses efeitos podem se dar, sobretudo, apenas devido ao efeito placebo. Em outras palavras, os cuidadores notam pequenas melhoras porque estão predispostos a isso quando são responsáveis por ministrar os medicamentos (GRADY, 2004).

Um dos resultados do atual impasse é que a pesquisa sobre demência está crescendo noutra direção. O espaço de tempo que agora interessa a muitos pesquisadores se estende para duas ou três décadas antes da idade em que a demência geralmente se instala, e o foco de atenção são as pessoas de meia idade ou mesmo mais novas - esses indivíduos que, acredita-se, podem muito bem estar começando a abrigar um ou mais dos endofenótipos atualmente reconhecidos como candidatos a biomarcadores dos primeiros sinais de um estágio de demência pré-clínica, prodrômica (BREITNER 1999; DEKOVSKY e MAREK, 2003). 
Os biomarcadores difíceis de se compreender são agora considerados por muitos como o núcleo ou a essência da doença. Alguns cientistas, sobretudo epidemiologistas interessados nos determinantes sociais da saúde, argumentam que a presença desses biomarcadores pode ser em parte produto dos efeitos de uma combinação de predisposição genética com tipos específicos de comportamento dos pais durante o início da vida intra-uterina e na infância que, juntos, afetam os circuitos cerebrais da criança e, conseqüientemente, a aptidão para a educação formal, que por sua vez promove efeitos negativos constituídos da "reserva cerebral". Ninguém duvida de que a idade é o maior fator de risco para a DA tardia. Essas teses são, na verdade, regressões finitas sobre idéias individualizadas, baseadas na idade e no curso de vida, sobre as causas da demência.

Artigo recentemente publicado em Public Health afirma que modelos lineares não contam a história toda. Colin Pritchard e colaboradores observam nesse artigo que, após controle para expectativa de vida ampliada, o número de mortes devido à demência se elevou nos últimos 20 anos na Europa, América do Norte e Austrália. Ainda mais surpreendente é o fato de que as mortes por demência estão ocorrendo em idades menos avançadas (PRITCHARD et al. 2004). Essas mudanças podem ser explicadas em parte pela aplicação de procedimentos diagnósticos mais rígidos. Mas Pritchard supõe, além disso, que os poluentes ambientais estão causando danos. Se este for o caso, isso explicaria o motivo pelo qual pessoas com nível educacional mais baixo, que sem dúvida ficam mais expostas aos poluentes, têm risco maior de apresentar DA - o que fornece argumento mais convincente que o usual, segundo o qual indivíduos com mais anos de educação formal são vulneráveis porque apresentam menos sinapses cerebrais e, assim, placas e emaranhados prejudicariam a insignificante quota de "reserva cerebral"5.

A afirmação segundo a qual pessoas que não receberam educação avançada apresentam menos sinapses em seus cérebros do que indivíduos com muitos anos de educação formal é questionável. Ademais é conveniente, para os pesquisadores, esquecer quem elaborou esses argumentos, dada a natureza da educação contemporânea, na qual as pessoas com muitos anos de escolaridade estão mais bem preparadas para lidar com testes neuropsiquiátricos aplicados em clínicas de memória e, além disso, que elas podem muito bem ser espertas o bastante para "encobrir" os primeiros sinais de demência, confundindo as estimativas sobre os grupos de risco. 


\section{Investigando a Demência Prodrômica}

Pesquisadores conhecidos no mundo das neurociências apontam que há, no momento, basicamente duas estratégias para se investigar biomarcadores de DA (DAFFNER e SCINTO, 2000). A doença de Alzheimer é uma condição que está associada sobretudo à perda de memória. Assim, numa abordagem, o foco da atenção são as regiões límbicas do cérebro, em especial no córtex entorrinal e no hipocampo - regiões do cérebro associadas à memória. Tecnologias de imagem são usadas para se detector essas alterações. A segunda maior estratégia é a monitoração dos subprodutos no sangue e no fluido cerebroespinhal dos primeiros sinais dos processos fisiopatológicos muito complexos associados à DA. Os cientistas reconhecem a natureza preliminar e as limtações dessas estratégias.

Em 1998, uma declaração de consenso intitulada "Molecular and Biomedical Markers of Alzheimer's Disease" foi apresentada pelo Ronald and Nancy Reagan Research Institute of the Alzheimer's Association e pelo National Institute on Aging Working Group (ver CONSENSUS REPORT, 2000). Observa-se que esses biomarcadores deveriam ter sensibilidade maior que $80 \%$ para detectar DA e, da mesma forma, uma especificidade maior que $80 \%$, de modo a serem confiavelmente distinguidos dos biomarcadores associados aos outros tipos de demência - considerando-se tudo o que já foi dito sobre as taxonomias dos fluidos, foi um desafio e tanto! A declaração aponta ainda que os biomarcadores desse tipo devem ser confiáveis, reproduzíveis, não-invasivos, simples de se realizar e econômicos. Em outras palavras, o objetivo final é isolar marcadores que possam ser prontamente detectados nos consultórios dos clínicos, talvez mesmo dos clínicos que trabalham em países em desenvolvimento. O termo biomarcador, empregado nesse relatório de consenso, inclui genes, endofenótipos e fenótipos clínicos. Dentre os marcadores citados encontram-se os seguintes: alterações neuropatológicas associadas ao início de depósito de excesso de amilóide, que resulta em formação de placas. Um segundo é a produção excessiva da proteína tau - a precursora das placas. O diagnóstico dessas duas alterações requer não apenas a neuroimagem, mas também um exame do fluido cérebro-espinhal - um procedimento altamente invasivo. A propaganda direcionada ao consumidor encoraja as pessoas a autotestarem em casa um outro biomarcador, usando kits de testes de odor destinados a detector mudanças no epitélio olfativo. E ainda outros biomarcadores são rastreados através de exames de sangue que detectam proteínas estruturalmente alteradas 
e alterações nas respostas pupilares, na forma como a pessoa escreve, anda etc. - tudo o que os pesquisadores consideram significativo.

A detecção desses biomarcadores é mais comum quando as pessoas participam de ensaios clínicos ou de pesquisa clínica, além de apresentarem a condição "descoberta" em 1994 e conhecida como Déficit Cognitivo Brando (MCI). Essa síndrome é a forma clínica da demência prodrômica. Descrita como "um estado transitório entre a cognição do envelhecimento normal e a demência branda", os expertos a reconhecem livremente como uma condição heterogênea; um ou dois estudiosos independentes se recusam a reconhecê-la como uma condição. A esperança é que, com base nos achados dos ensaios clínicos, sejam criados subtipos de pacientes - aqueles com MCI que passaram a apresentar DA, e aqueles cujo declínio cognitivo é considerado "normal" e que não evoluem para uma patologia completa. Achados de neuroimagem, de testes neuropsiquiátricos, detecção de alterações moleculares precoces e genotipagem criam conjuntos de saberes que constituem esse novo espaço de adivinhação (JOURNAL OF INTERNAL MEDICINE, 2004). Completamente molecularizado, esse espaço está decidamente ligado à idéia de declínio linear relacionado à idade numa patologia que pode ser diferenciada do envelhecimento normal baseado em extenso monitoramento. Espera-se que a busca exaustiva por endofenótipos resulte no estabelecimento de limites claros e a normalização da demência prodrômica, incipiente ${ }^{6}$.

Esse modelo dá muito pouca importância às considerações sobre a contribuição dos ambientes social e físico à doença, nas milhares de pessoas diagnosticadas com déficit cognitivo brando; ele apenas faz uma breve menção às interações gene-ambiente, e trabalha na suposição de que o cérebro é algo como um músculo, um órgão que precisa ser flexionado e exercitado regularmente; o comportamento individual é considerado uma resposta direta à atividade sináptica (LeDOUX, 2002), e níveis mais altos de articulação - mente, relações familiares, respostas societais ao envelhecimento e à demência, ambientes tóxicos - são deixados de lado.

\section{A Genética da Doença de Alzheimer}

Sabe-se há mais de vinte anos que raros genes autossômicos dominantes estão inevitavelmente associados com o que se conhece como "doença de Alzheimer precoce". Essa forma de DA - observada inicialmente por Alois 
Alzheimer - há muito foi conceituada como uma "doença genética," embora a idade do início em gêmeos idênticos possa variar em até uma década (TILLEY et al., 1998). Em 1991, um polimorfismo específico do gene APOE, presente em todos os mamíferos, localizado no cromossomo 19 dos seres humanos, foi pela primeira vez associado com o maior risco de início tardio da DA comum. Esse achado levou a se reconsiderar o pensamento de então, segundo o qual a doença de Alzheimer em pessoas idosas é "esporádica" e não "herança familiar". Recentemente, como resultado dos achados da biologia molecular, esse pensamento mudou mais uma vez.

Agora existe amplo consenso entre os pesquisadores, de que pelo menos três caminhos moleculares complexos levam a uma via final comum, cujo fim é a doença de Alzheimer, e é ao longo dessas vias tributárias que se dá a busca por outros genes envolvidos e biomarcadores. A primeira via começa no início da meia-idade, quando um dos genes específicos associados ao início precoce da DA é ligado. Tais mutações são encontradas em cerca de 170 famílias ao redor do mundo. Uma segunda via, muito mais comum, envolve o gene APOE. Esse gene tem três ou talvez quatro variações polimórficas que se distribuem desigual mas universalmente pela população humana, nas quais o alelo e4 está envolvido. Pouco tempo depois das primeiras afirmações, feitas no início dos anos 1990, sobre a associação entre esse alelo e o maior risco de DA, houve discordâncias. Hoje todos os pesquisadores e clínicos concordam que o alelo APOEe4 é um gene de susceptibilidade para DA, mas que, embora importante, não é necessário nem suficiente para causar a doença. A maior parte da pesquisa relacionada ao APOE foi desenvolvida em populações de caucasianos, e há suficientes razões para se suspeitar que o alelo e4 pode ser fator protetor em ambientes onde dominam outros grupos de genes que não os formados por DNA caucasianos, o que aumenta sua complexidade (CORBO e SCACCHI, 1999). A pesquisa clínica sobre o alelo e4 mostra que quando este está implicado na DA, essa mesma "trilha final comum" é movimentada pelos genes autossômicos dominantes, mas essas mudanças se manifestam mais adiante no curso da vida (SELKOE, 2000).

Considerando-se que em pelo menos $50 \%$ dos casos diagnosticados de DA tardia os pacientes não apresentam o alelo APOEe4, deve haver pelo menos uma outra via para a DA. Supõe-se que essa via seja formada por genes que interagem mutuamente, e por DNA não-codificado junto com fatores ambientais internos e/ou externos ao corpo. Essa terceira alternativa também 
resulta na mesma via final comum, com o típico resultado final que são placas e perda celular. Levando-se em conta que genes "não descobertos" até agora estejam sem dúvida implicados, a caçada genética continua sendo importante para os pesquisadores, e diversos "genes candidatos" estão sendo investigados devido a sua possível contribuição para a DA.

Dois geneticistas especializados em desordens neurodegenerativas assim resumiram recentemente a situação atual: "Em primeiro lugar e mais importante, a hereditariedade da DA é alta... isso foi comprovado em vários estudos... nas últimas décadas" (BERTRAM e TANZI, 2004, p. R-135). Os autores continuam então a criticar a maior parte da pesquisa que está sendo desenvolvida sobre a genética da DA, e culpam a metodologia, a falta de respostas e o descaso em relação à estrutura haplotípica. Utilizando a base de dados PubMed, eles mostram que, só em 2003, foram realizados 1.037 estudos sobre a genética da DA; destes, 55 genes analisados foram positivamente associados com o maior risco da doença, e 68 foram negativos. Genes candidatos foram examinados em cada um dos cromossomas. Bertram e Tanzi, com excessiva cautela, concluem: "enquanto a associação genética per se [do APOEe4 com a DA] foi muito bem demonstrada na última década, não existe consenso sobre como essa associação traduz patofisiologicamente", nem como ela funciona junto com os diversos outros genes candidatos" (BERTRAM e TANZI, 2004, p. R-137). Esse confuso estado de coisas talvez explique por que, na mais recente conferência internacional sobre DA, realizada na Filadélfia (EUA), em 2004, as sessões mais concorridas não fossem as que tratavam de genética (como foi o caso de Estocolmo, em 2002), mas as que falavam de biomarcadores e Déficit Cognitivo Brando. No entanto, não há uma economia política da esperança associada a essa doença. Alguns poucos pesquisadores acham que haverá um avanço em um ou dois anos, a maioria diz que em cinco ou dez anos, e ainda há aqueles que pensam que nós estamos lutando uma batalha perdida.

\section{Testando os Genes da Doença de Alzheimer}

A testagem genética já é oferecida como rotina às poucas pessoas cujas famílias apresentam caso de DA precoce; a pesquisa científica básica sobre esses genes é reconhecidamente forte e, devido ao fato de que os indivíduos afetados podem ter que decidir sobre questões reprodutivas, assim com se preparar para o futuro, a testagem é considerada adequada, da mesma 
forma que no caso da doença de Huntington (ALMQIST et al., 2003; KONRAD, 2005).

A situação é um pouco diferente no caso da DA tardia. Sem exceção, as normas oficiais na América do Norte, no Reino Unido, na França e em alguns outros lugares são atualmente contrárias à testagem rotineira dos alelos APOE. Essa recomendação se justifica facilmente, considerando-se que as avaliações de risco individuais para a DA tardia que utilizam a genética são tão vagas que podem ser consideradas, pela maioria dos clínicos e pesquisadores, de pouco ou nenhum uso no cuidado clínico (FARLOW, 1997; LIDDELL et al., 2001; McCONNELL et al,. 1998; St. GEORGE-HYSLOP, 2000; TILLEY et al., 1998). Conhecer o genótipo de um paciente não surte qualquer efeito sobre o cuidado clínico ou prognóstico, embora isso seja usado ocasionalmente no apoio a prováveis diagnósticos de DA.

Entretanto, na realidade, as normas nem sempre são seguidas: diversas companhias privadas oferecem testagem para APOE, e um kit chamado "Early Alert Alzheimer's Home Screening Test" é vendido diretamente aos consumidores (KIER e MOLINARI, 2003). Pelo menos uma clínica de repouso na Carolina do Norte não aceita idosos que não tenham sido submetidos a um teste de APOE. Idosos candidatos a viver na instituição cujos testes tenham dado positivo para APOEe4 são recusados sob a alegação de que eles tendem a se tornar dementes e problemáticos, embora essa situação já tenha sido levada inclusive à Justiça (THOMAS et al,.1998).

Marcar o início da comercialização dos testes é difícil, e a maior parte dos testes de APOE acontece em centros de pesquisa, onde a análise de genótipos é normalmente realizada em quase todos os clientes e pacientes das diversas clínicas de memória que proliferaram nos últimos anos, associadas aos departamentos de neurologia de hospitais terciários da América do Norte e da Europa. Os pacientes, e em alguns casos seus parentes em primeiro grau, quando concordam em participar de pesquisas sobre DA, normalmente sabem que os testes incluem genotipagem para APOE e talvez para outros genes. Entretanto, esses indivíduos são informados de que, embora a genotipagem seja essencial para fins de pesquisa, registrar o conhecimento de alguém sobre seu DNA na verdade não tem valor algum. Termos de consentimento são assinados, e neles se afirma que não se dará informação sobre genotipagem, nem aos pacientes nem aos seus médicos, embora às vezes escape alguma informação. 
Se esse tipo de teste se libertasse do constrangimento imposto pelos protocolos de pesquisa, e fosse introduzido nas clínicas para uso rotineiro, como é o objetivo final, os pacientes e seus familiares teriam que ser informados dos resultados da tipagem de DNA, e as estimativas dos riscos de DA seriam discutidas com eles. A forma como esse risco será calculado será sempre suspeita, porque se entende tão pouco sobre epigenética das doenças complexas, e as demências estão se revelando particularmente teimosas nesse sentido. Esses cálculos constituirão os "riscos que não podem ser conhecidos" (BECK, citado por YATES, 2003, p. 96) e dificilmente podem ser considerados um conhecimento previsível sobre o qual indivíduos e familiares podem agir. No entanto, é bastante evidente que, caso se encontre um medicamento que atue seletivamente sobre um tipo de polimorfismo de APOE, como é o desejo de companhias que trabalham com farmacogenética, então cada paciente será testado individualmente. Esse será um pequeno passo na direção da testagem rotineira de parentes não afetados pela doença.

É óbvio que, se o conhecimento científico sobre a genômica molecular humana, a proteômica e a epigenética está avançando, sobretudo no que diz respeito à medicina preventiva e à farmacogenética, então os pesquisadores têm que estudar amostras de DNA em milhares de voluntários (estima-se que 500 sujeitos e 500 controles são necessários em cada projeto de pesquisa [BERTRAM e TANZI, 2004]) e, considerando-se a quantidade de testes que já ocorre, não causa surpresa que alguns médicos afirmem que parentes de pacientes com DA cada vez mais desejam ser genotipados. Recente pesquisa telefônica feita com 314 pessoas nos Estados Unidos encontrou que 80\% dos respondentes afirmaram desejar ser geneticamente testados para DA se lhes fosse assegurado que o teste é preciso e se fossem informados da predisposição familiar para essa doença (NEUMANN et al., 2001). E mais, a natureza litigiosa da sociedade norte-americana trabalha no sentido de encorajar a testagem: três processos judiciais foram movidos contra médicos nos Estados Unidos, por eles terem deixado de alertar famílias sobre os riscos de doenças hereditárias em adultos (OFFIT et al., 2004).

\section{O Projeto REVEAL}

Os Institutos Nacionais de Saúde (NIH) aprovaram um ensaio controlado randomizado, conhecido como REVEAL (Risk Evaluation and Education for Alzheimer's disease - Avaliação de Risco e Educação para a Doença de 
Alzheimer), no qual voluntários são testados para o gene APOE. Uma das justificativas do projeto é avaliar como as pessoas reagem ao serem informadas de que têm o gene que os cientistas acreditam causar o maior risco da doença de Alzheimer tardia. A segunda justificativa é a suposição de que a testagem para susceptibilidade genética tende a se tornar mais comum, sobretudo no setor privado, e assim o conhecimento sobre o modo como as pessoas lidam com a informação sobre o risco quando é impossível prever com segurança se torna mais urgente. Uma terceira justificativa é que omitir das pessoas informação sobre seu próprio corpo seria algo condescendente, e a quarta é que em muitas famílias nas quais alguém tenha morrido devido à $\mathrm{DA}$, os membros das gerações seguintes podem vir a acreditar que têm $100 \%$ de chance de contrair a doença. Se os indivíduos puderem ser ensinados, mesmo que sejam homozigóticos para o ApoEe4, o risco de contraírem DA nunca é maior do que cerca de 50\% - assim os níveis de ansiedade podem muito bem ser reduzidos. A justificativa final, e talvez a mais importante, é criar um grupo de indivíduos com ApoEe4 cujos sangues possam ser usados a qualquer tempo para enriquecer ensaios clínicos.

Famílias nas quais um ou mais membros tenham sido afetados pela DA tardia são o foco dessa pesquisa, e elas estão sendo recrutadas tanto através da verificação sistemática dos registros de DA nos Estados Unidos, localizados nas universidades de Boston, Case Western Reserve e Cornell, ou através da auto-referência em cada um desses locais (CUPPLES et al., 2004). Os voluntários da pesquisa estão praticando o que caracterizo como cidadania corpórea, e acreditamos que, através da contribuição deles, a pesquisa poderá ajudar muito a sociedade e, ainda, ajudar talvez sua família ou eles próprios no futuro. Através do recrutamento, os indivíduos são randomizados em grupos de intervenção e controle, e todos assistem a uma apresentação educativa que inclui informação sobre susceptibilidade genética. Eles são convidados a retornar posteriormente ao local da pesquisa, para coleta de sangue, após a qual os sujeitos são informados sobre seu status de ApoE. Os sujeitos considerados controles não recebem essa informação, embora seu sangue também tenha sido coletado. Nos 12 meses seguintes, é feito o monitoramento sistemático das reações dos participantes do projeto, através de três entrevistas estruturadas. Um subgrupo da amostra, composto por 55 indivíduos, se propôs a voltar quando o estudo REVEAL básico estiver completo, para se submeter a entrevistas abertas semi-estruturadas ${ }^{7}$. Deve-se observar que os participantes do projeto REVEAL têm 17 anos completos de educação formal, média consideravelmente maior do que os Estados Unidos como um todo. 
Como parte da sessão de aconselhamento, os sujeitos da pesquisa recebem "avaliações de risco personalizadas" para DA, em forma de gráficos baseados em idade, histórico familiar, gênero e, para os que fizeram parte do braço experimental do projeto, sobre tipagem de DNA. Na época das entrevistas qualitativas, mais de 12 meses após terem recebido informação sobre o risco estimado, os participantes, quase sem exceções, transformaram as estimativas em registros que se "encaixam" com sua própria experiência de estar ligado a alguém que tem a doença de Alzheimer, com sua avaliação individual do histórico familiar e seu conhecimento acumulado sobre a doença, conseguido a partir de diversas fontes. Em outras palavras, as estimativas de risco proporcionadas pelo estudo REVEAL raramente deslocam o "conhecimento leigo" que os participantes trazem para o projeto. Isso pode explicar em parte o número relativamente pequeno de participantes do REVEAL (33\%) que conseguem se lembrar das estimativas de risco que lhes foram informadas - o que é especialmente digno de nota quando $91 \%$ afirmaram que "querer conhecer" seu genótipo foi a motivação maior para participar do projeto, além do desejo de contribuir para a pesquisa científica.

\section{A Genética e a Herança Misturada}

A pesquisa em ciências sociais registrou bastante a maneira como os indivíduos interpretam a informação que recebem sobre seu genótipo, e muitas vezes resistem a se apoiar apenas nas explicações genéticas para dar conta das doença que afetam suas famílias (CONDIT, 1999). Além disso, quando a informação genética é incorporada aos dados sobre as causas da doença, essas informações complementam idéias antigas sobre parentesco, hereditariedade e saúde. Por exemplo, Cox e McKellin (1999, p. 130) demonstraram que a compreensão dos leigos sobre hereditariedade em geral colide com a teoria da genética mendeliana, porque explicações científicas se mostraram inadequadas para famílias que lidam com a experiência vivida do risco genético. Kerr sugere que é razoável aceitar que leigos são sua própria autoridade quando se trata de apreciar e compreender como a genética pode moldar suas vidas (KERR et al., 1998).

Até agora, a maior parte da pesquisa em ciências sociais dentro das ramificações sociais da nova genética se concentrou no impacto da transmissão de informação sobre genes específicos que produzem desordens de um modo altamente (mas não 100\%) previsível de transmissão mendeliana. A situação é 
bastante diferente quando os genes de susceptibilidade estão envolvidos, porque as estimativas de risco, como observado acima no caso de DA, se baseiam em cálculos de probabilidade que em geral possuem pouco poder de explicação. Para aumentar a complexidade, o entendimento profissional sobre a genética molecular da doença complexa é mais bem descrito como "conhecimento-emfluxo", com o resultado que as variáveis nas quais as estimativas de probabilidade se baseiam são continuamente revisadas. Não estamos lidando com "questões estabelecidas", mas com informação provisória, que deverá, por sua vez, ser traduzida em estimativas que supostamente refletem os melhores casos individuais.

Se, como mostrado acima, as explicações profissionais sobre os riscos relacionados às doenças mendelianas não resultam no tipo de entendimento e comportamento esperados, mesmo quando há aconselhamento genético profissional (HILL, 1994; RAPP, 1999), qual será a situação relativa à genética das doenças complexas? Os resultados do projeto REVEAL e de pesquisas paralelas realizadas em Montreal, onde parentes de pacientes com Alzheimer não são geneticamente testados (LOCK et al., no prelo), sugerem que as pessoas em geral recorrem a um conceito de "herança misturada"," uma forma de pensar que remonta aos tempos clássicos (TURNEY, 1995, p. 12), quando tentam interpretar as probabilidades que o genótipo lhes oferece. Esse conceito ainda é altamente prevalente hoje em dia, e assume uma combinação de entidades que passam de geração a geração de forma agrupada. As semelhanças fenotípicas compartilhadas pelos membros das famílias - aspectos físicos, padrões de personalidade etc. - indicam que esses mesmos indivíduos também estão propensos a desordens presentes em suas famílias". No que diz respeito às desordens ligadas a um único gene, já se demonstrou que essa idéia é mais comum do que aquela que considera, segundo Mendel, que o genótipo determina a expressão fenotípica (RICHARDS, 1996, p. 222). As entrevistas qualitativas do estudo REVEAL sugerem - e isso não é surpresa - que a herança misturada foi amplamente utilizada para interpretar as estimativas de risco para DA com base no status de APOE e histórico familiar.

A incerteza associada a estimativas de risco para a grande maioria dos participantes do REVEAL se situa muito abaixo de um risco adicional de 50\% aos 85 anos de idade, se comparados à população como um todo, aliado à doença tardia, que dá margem aos indivíduos pesquisados para criar suas próprias narrativas sobre se eles são verdadeiramente vulneráveis ou não. Além disso, esses indivíduos sabem, através da mídia e também por outros meios, além das 
sessões educativas do projeto REVEAL, que a DA tardia possui diversas causas que não são compreendidas, e que a susceptibilidade genética, embora contribua, não determina o futuro. Soma-se a isso a falta de capacidade de alguns participantes, apesar dos muitos anos de educação formal, para compreender realmente o que lhes está sendo dito sobre risco e o gene APOE. Todas as pessoas que participaram do REVEAL foram informadas sobre o que é viver com a doença de Alzheimer, e muitas delas cuidam do familiar doente; é essa experiência sobretudo que dá o tom em suas respostas sobre genotipagem. Por exemplo, Carolyn, enfermeira psiquiátrica, e sua irmã fazem parte do grupo randomizado que recebeu o status de ApoE. Carolyn foi informada de que possui um genótipo 3/3, enquanto sua irmã possui uma única cópia do alelo e4. Quando perguntada sobre o teste, Carolyn respondeu: "Honestamente, não penso sobre isso, porque quando penso me vêm à cabeça os fatores de risco de minha irmã - passei por isso com meu pai. Não quero nem pensar em passar por isso com ela também".

Quando perguntada sobre sua reação aos próprios resultados, Carolyn responde: "Não pensei nisso quando soube do meu fator de risco... Acho que eu não me lembro de muita coisa". E ainda assim ela também justifica sua participação no REVEAL, em função de desejar conhecer seu genótipo: "Conhecimento é poder. Acredito nisso. Quer dizer, não acho que a gente consiga mudar o destino, mas viver a vida com os olhos só meio abertos não ajuda em nada...". Em relação à pergunta sobre que tipos de ação esse poder poderia motivar, Carolyn se mostra insegura: "Acho que ele [o REVEAL] dá muita informação útil. Só não me pergunte como eu a utilizaria, honestamente, não sei...".

Durante o curso de enfermagem, Carolyn fez duas disciplinas sobre genética, o que sem dúvida contribuiu para sua capacidade de lembrar o que aprendeu durante as sessões do REVEAL, ao contrário de outros participantes do projeto. Laura, que trabalha como professora numa escola, foi informada de que tinha um genótipo 4/4. Ela comenta.

"Acho que eu pensava (antes do REVEAL) que eu tinha 90\% de chance de ter isso [DA]. Agora sei que minha chance é de 50\%, então é 'cara ou coroa'. Participei dessas oficinas, mas ainda estou [totalmente] confusa. Sei que tenho duas coisas ruins, o que quer que elas sejam. E tenho uma pelo lado de minha mãe e outra pelo lado de meu pai. Então não sei se, aos 70 anos, terei $50 \%$ de chance de ter DA, o que não me parece tão mau, a não ser pelo 
fato de que a maioria das pessoas tem $10 \%$ de chance quando chegam aos 70 anos. Não é tão bom assim”.

Quando pedimos que explicasse o que seriam "essas coisas ruins", Laura respondeu: "Não sei. Não sei que gene é... Não é o gene BRCA". Outras pessoas se mostraram igualmente confusas, e umas duas usaram de sarcasmo para falar sobre o que sentiram ao ser genotipadas: "Entendo de genética básica, Mendelssohn, plantas etc. Agora sei que o ApoE4 é ruim e que tenho um, mas não sei por que ele é ruim e o que ele faz". Ou: "Bem, sei onde estou. Posso dizer a meus filhos onde estamos. Quer dizer, posso ter isso, ou posso não ter...".

Para diversos participantes, a informação fornecida pelo REVEAL entrava em conflito com sua própria compreensão sobre o futuro. Rebecca, cujo genótipo é $3 / 3$ e que tem quatro parentes doentes, insiste:

"De acordo com aquilo [o teste de DA], não corro risco, certo? Então, tecnicamente, eu deveria me sentir melhor. Mas não acredito nisso. Se eu tivesse toda a confiança do mundo naquele teste, diria 'Talvez isso não aconteça', mas não penso assim, e mesmo que o teste dissesse 'Você vai ter isso', não faria a menor diferença porque eu acho que teria de qualquer maneira...".

Quando perguntados sobre o que seria a causa da DA, os entrevistados, quase sem exceção, apontam diversas causas, embora a genética seja mais forte que as outras, seguida pelo meio ambiente, dieta e o alumínio (causa não mais endossada pelos cientistas). Depois se seguem diversas outras causas, que incluem depressão, estresse, falta de atividade mental ou física e idade. No entanto, mesmo uma breve elaboração do discurso mostra como as idéias sobre genética estão incrustadas em registros narrativos complexos. Uma entrevistada de 52 anos, que participou do grupo controle e, logo, não sabia do seu status de APOE, assim expressa seus pensamentos:

"Se acho que tenho uma chance mais do que a média? Sim. Hereditariedade. Sou muito parecida com minha mãe. E eu diria a ela, 'mãe, espero não ser parecida com você nesse ponto'. Sei que ela teve Alzheimer. Isso é um fato. Assim, há grandes chances de que um ou mais filhos dela tenham predisposição à doença. E posso afirmar que sou a primeira colocada, porque sou parecida com minha mãe em muitas coisas". 
Jane, cuja tipagem é de $3 / 3$ e possui um parente com a doença, comenta:

"Tenho - nem sei por quê - nem mesmo me lembro, porque isso significa tão pouco para mim... Meu risco antes dos 85 anos é muito menor do que para outras pessoas. Após os 85 , é cerca de $15 \%$ maior. Isso não faz sentido para mim... Acho realmente que não tenho muita chance de não ter [DA] por causa da genealogia. Quando olho para ambos os lados de minha família, toda a família materna - só tem Alzheimer. Do lado de meu pai não tem Alzheimer. Só problema do coração e colesterol e triglicerídeos altos. Bem, eu me pareço com minha mãe".

Outra pessoa do grupo controle, que não estava satisfeita porque não fazia parte do grupo que foi genotipado, também recorreu à herança misturada para justificar sua preocupação:

"Mostrei a minha foto e a de meu pai. Somos praticamente como clones. E ninguém nunca disse - não sei se a informação está lá porque nunca a li - se faz ou não diferença a aparência física de uma pessoa. Mas desconfio que faz".

\section{E um outro paciente comentou sobre seu irmão:}

"Meu irmão está muito preocupado. Ele não tem muito conhecimento científico, e tende a achar que herdou muita coisa de nossa mãe. Eles têm a mesma cor de cabelo e dos olhos, assim como muitos traços de comportamento. Não quero depreciar meu irmão, mas é assim que ele pensa”.

Apesar da grande propensão para criar fatos que incorporem idéias sobre a herança misturada, a maioria dos respondentes não se baseia apenas na genética; muitas vezes há comentários como os que se seguem:

"Acho que a genética faz parte, mas não acho que seja o fim de tudo. Tenho certeza de que o cuidado com a dieta, com a saúde e o exercício que fazemos irão prolongar a vida e a acuidade mental".

"É um tipo de roleta-russa. Tudo parece estar trabalhando contra você, não importam quais sejam os fatores. E ainda não sei o que é. Talvez o alumínio em seus dentes? Ouvimos coisas assim, não sei direito".

Dentre os indivíduos que se baseiam em teorias da herança misturada, 
persiste a crença de que a biologia é destino, apesar da participação no projeto REVEAL, ao contrário do aconselhamento profissional e do que se sabe sobre a genética da DA, e mesmo dos resultados dos testes. Por outro lado, algumas pessoas aparentemente vão embora reasseguradas de que elas não têm um risco tão grande, o que é sem dúvida uma boa coisa, a não ser que elas estejam seguras demais e acreditem que não são no final das contas vulneráveis à doença.

É claro que a pesquisa sobre endofenótipos, biomarcadores e genes de susceptibilidade associados é importante, mas permanece aberta a questão se é condescendente esconder dos indivíduos os resultados de sua genotipagem, a não ser que a transmissão dos detalhes do que são com efeito incertezas insolúveis tiver algum valor. As entrevistas com os sujeitos do REVEAL indicam que maquiar incertezas serve apenas para reforçar as crenças altamente sedutoras, mas completamente antiquadas, pelo menos no que diz respeito à biologia molecular, sobre a herança misturada. Embora poucas famílias acreditem que a genética seja a única causa da DA, o perigo de se rotinizar a testagem genética e informar as pessoas sobre seu status de APOE é que essa prática irá desviar a atenção, tanto dos médicos quanto do público, das questões desafiadoras levantadas pela epigenética, inclusive o motivo por que tantas pessoas com o polimorfismo e4 não têm DA.

\section{Referências}

ALMQVIST, Elisabeth; et al. Risk Reversals in Predictive Testing of Huntington Disease. American Journal of Human Genetics v. 61, p. 945-952, 1997.

ANGELL, Marcia. The Truth About the Drug Companies. New York Review of Book, v. 51, p. 52-58, 2004.

ARMSTRONG, H. E. The Monds and Chemical Industry: A Study in Heredity. Nature, v. 128, p. 238, 1931.

BERG, Paul. All Our Collective Ingenuity will be needed. Federation of American Societies for Experimental Biology, v. 5, p. 75-77, 1991.

BERTRAM, Lars; TANZI, Rudolph E. Alzheimer's Disease: One Disorder, Too Many Genes? Human Molecular Genetics, v.13 (R1), p. R135-R1, 2004. 
BREITNER, John C. The End of Alzheimer's Disease? International Journal of Geriatric Psychiatry, v. 14, p. 577-586, 1999.

CHAMPAGNE, F.; MEANY, M. Like Mother, Like Daughter: Evidence for Non-Genomic Transmission of Parental Behavior and Stress Responsivity. Progress in Brain Research, v. 133, p. 287-302, 2001.

CONDIT, C. M. How the Public Understands Genetics: Non-Deterministic and Non-Discriminatory Interpretations of the "Blueprint" Metaphor. Public Understanding of Science, v. 8, p. 169-180, 1999.

COX, S.; McKELLIN, W. 'There's this Thing in our Family': Predictive Testing and the Construction of Risk for Huntington Disease. In: CONRAD, P.; GABE, J. (Eds.). Sociological Perspectives on the New Genetics, London: Blackwell Publishers, 1999.

CUPPLES, L. A.; et al Estimating Risk Curves for First-degree Relatives of Patients with Alzheimer's Disease: The REVEAL Study. Genetics in Medicine, v. 6, p. 192-196, 2004.

DAFFNEr, Kirk R.; SCINTO, L. F. M. Early Diagnosis of Alzheimer's Disease: An Introduction. In: SCINTO, L. F. M.; DAFFNER, K. R. Early Diagnosis of Alzheimer's Disease. Totowa, New Jersey: Humana Press, 2000.

DAVIS, B. D. The Human Genome and Other Initiatives. Science, v. 4, p. 2.941-2.942, 1990.

DENNET, Daniel Clement. Darwin's Dangerous Idea: Evolution and the Meanings of Life. New York: Simon \& Schuster, 1995.

DUSTER, Troy. Back Door to Eugenics. New York: Routledge, 1990.

DUTTON, Gail. Learning the Secrets of Life. Engineering News, v. 23, p. 657, 2003.

EDDY, Sean R. Non-Coding RNA Genes and the Modern RNA World. Nature Reviews/Genetics, v. 2, p. 919-929, 2001.

FARLOW, Martin R. Alzheimer's Disease: Clinical Implications of the Apolipoprotein E Genotype. Neurology, v. 48, p. S30, 1997.

FOX KELLER, Evelyn. Is There an Organism in This Text? In: SLOAN, P. (Ed.). Controlling our Destinies: Historical, Philosophical, Ethical, and Theological Perspectives on the HGP. South Bend: Notre Dame University Press, 2000a. 
. The Century of the Gene. Cambridge: Harvard University Press, $2000 \mathrm{~b}$.

. Making Sense of Life: Explaining Biological Development with Models, Metaphors and Machines. Cambridge: Harvard University Press, 2002.

GIBBS, W. Wayt. The Unseen Genome: Gems Among the Junk. Scientific American v. 289, n. 5, p. 47-53, 2003.

GILBERT, Scott F. The Genome in Its Ecological Context: Philosophical Perspectives on Interspecies Epigenesis. Annals of the New York Academy of Sciences, n. 981, p. 202-218, 2002.

GOTTESMAN, Irving. Schizophrenia Epigenesis: Past, Present and Future. Acta Psychiatrica Scandinavia, v. 90, n. 384, p. S26-S33, 1994.

GOTTESMAN, I. I.; SHIELDS, J. Schizophrenia and Genetics: A Twin Study Vantage Point. New York: Academic Press, 1972.

GRADY, Denise. Nominal Benefits Seen in Drugs for Alzheimer's. The New York Times, April 7, 2004.

GUDDING, Gabriel. The Phenotype/Genotype Distinction and the Disappearance of the Body. Journal of the History of Ideas, v. 57, n. 3, p. 525-545, 1996.

HILL, Shirley. Managing Sickle Cell Disease in Low-Income Families. Philadelphia: Temple University Press, 1994.

JACOB, Francois; MONOD, Jacques. Genetic Regulatory Mechanisms in the Synthesis of Proteins. Journal of Molecular Biology, v. 3, p. 316-356, 1961.

JOHANNSEN, Wilhelm. Some Remarks About Units in Heredity. Hereditas, v. 4, p.133-141, 1923.

KAY, Lily E. The Molecular Vision of Life: Caltech, the Rockerfeller Foundation and the New Biology. Oxford: Oxford University Press, 1993.

KERR, A., CUNNIGHAM-BURLEY, S.; AMOS, A. The New Human Genetics and Health: Mobilizing Lay Expertise. Public Understanding of Science, v. 7, p. 41-60, 1998.

KIER, F. J.; MOLINARI, V. “Do-it-Yourself” Dementia Testing: Issues Regarding an Alzheimer's Home Screening Test. The Gerontologist, v. 43, p. 295-301, 2003. 
KITCHER, Philip. The Lives to Come: The Genetics Revolution and Human Possibilities. New York: Simon and Schuster, 1996.

KONRAD, Monica. Narrating the New Predictive Genetics: Ethics, Ethnography and Science. In: ROSE, N.; RABINOW, P. Cambridge Studies in Society and the Life Sciences. Cambridge: University of Cambridge Press, 2005.

LE DOUX, Joseph. Synaptic Self: How our Brains Become Who We Are. London: Penguin Books, 2002.

LEWONTIN, Richard C. Science and Simplicity. New York Review of Books, v. 50, n. 7, p. 39-42, 2003.

LIDDELL, M. B.; LOVESTONE, S.; OWEN, M. J. Genetic Risk of Alzheimer's Disease: Advising Relatives. British Journal of Psychiatry, v. 178, p. 7-11, 2001.

LOCK, Margaret; et al. When It Runs in the Family: Putting Susceptibility Genes into Perspective (no prelo).

LOCK, Margaret; LLOYD, Stephanie; PREST, Janalyn. Genetic Susceptibility and Alzheimer's Disease: The 'Penetrance' and Uptake of Genetic Knowledge (no prelo).

MATE, Gabor. 'Was that Trademark Smile the First Sign of Alzheimer's?' Globe and Mail, June 12th, 2004.

MATTICK, John S. Challenging the Dogma: the Hidden Layer of Non-Protein-Coding RNAs in Complex Organisms. BioEssays, v. 25, p. 930-939, 2003.

. The Hidden Genetic Program of Complex Organisms. Scientific American, v. 29, p. 60-67, 2004.

MCCONNELL, L.M.; et al. Genetic Testing and Alzheimer's Disease: Has the Time Come? Nature Medicine, v. 4, p. 757-759, 1998.

NEUMANN, P. J.; et. al. Public Attitudes About Genetic Testing for Alzheimer's Disease. Health Affairs, v. 20, n. 5, p. 252-264, 2001.

OFFIT, Kenneth; et. al. The "Duty to Warn" a Patient's Family Member About Heredity Disease Risks. Journal of the American Medical Association, v. 292, p. 1.469-1.473, 2004. 
PETRONIS, Arturas. Human Morbid Genetics Revisited: Relevence of Epigenetics. Trends in Genetics, v. 17, p. 142-146, 2001.

PRITCHARD, C.; BALDWIN, D.; MAYERS, A. Changing Patterns of Adult (45-74 years) Neurological Deaths in the Major Western Countries 1979-1997. Public Health, v. 118, p. 268-283, 2004.

RAPP, R. Testing Women, Testing the Fetus: The Social Impact of Amniocentesis in America. New York: Routledge. 1999.

RHEINBERGER, Hans-Jorg. From Microsomes to Ribosomes: 'Strategies' of 'Representation' 1935-1955. Journal of the History of Biology, v. 28, p. 4989, 1995.

RICHARDS, Martin. Lay and Professional Knowledge of Genetics and Inheritance. Public Understanding of Science, v. 5, p. 217-230, 1996.

SAPP, Jan. The Struggle for Authority in the Field of Heredity, 1900-1932: New Perspectives on the Rise of Genetics. Journal of the History of Biology, v.16, n. 3, p. 311-342, 1983.

SCHMIEDESKAMP, Mia. Preventing Good Brains from Going Bad. Scientific American, v 14, p. 84-91, 2004.

SILVER, M. H; et al. Distinguishing Between Neurodegenerative Disease and Disease-Free Aging: Correlating Neuropsychological Evaluations and Neuropathological Studies in Centenarians. Psychosomatic Medicine, v. 64, p. 493$501,2001$.

SNOWDON, David. Aging with Grace: What the Nun Study Teaches us About Leading Longer, Healthier, and More Meaningful Lives. New York: Bantam Books, 2001.

ST. GEORGE-HYSLOP, P. H. Molecular Genetics of Alzheimer's Disease. Biological Psychiatry, v. 47, p. 183-199, 2000.

SWARTZ, R. H.; BLACK, S E.; ST. GEORGE-HYSLOP. P. ApolipoproteinE and Alzheimer's Disease: a Genetic, Molecular and Neuroimaging Review. Canadian Journal of Neurological Sciences, v. 26, p. 77-88, 1999.

THOMAS, A. Mathew; et al. Alzheimer Testing at Silver Years. Cambridge Quarterly of Healthcare Ethics, v. 7, p. 294-307, 1998. 
TILLEY, L.; MORGAN, K.; KALSHEKER, N. Genetic Risk Factors in Alzheimer's Disease. Journal of Clinical Pathology: Molecular Pathology, v. 51, p. 293-304, 1998.

TURNEY, Jon. The Public Understanding of Genetics - Where Next? European Journal of Genetics and Society, v. 1, p. 5-22, 1995.

WATSON, James; CRICK, Francis. The Structure of DNA. Cold Spring Harbor Symposia on Quantitative Biology, v. 18, p. 123-131, 1953.

WHITEHOUSE, Peter J. The End of Alzheimer Disease. Alzheimer Disease and Associated Disorders, v. 15, n. 2, p. 59-62, 2001.

YATES, Joshua. An Interview with Ulrich Beck on Fear and Risk Society. Hedgehog Review, v. 5, p. 96-107, 2003. 


\section{NOTAS}

* Professora do Departamento de Estudos Sociais em Medicina e Departamento de Antropologia, McGill University, Canadá. Endereço eletrônico: margaret.lock@ mcgill.ca.

${ }^{1}$ No original: "The molecularized mind and the search for incipient dementia". Tradução de Ana Silvia Gesteira. Revisão técnica de Kenneth R. de Camargo Jr.

${ }^{2}$ Muitos genes são polimórficos e apresentam grandes variações, que se espalham pelas populações humanas. Esses polimorfismos, que estão associados ao maior risco de se desenvolver uma desordem, são conhecidos como "genes de susceptibilidade". Essas variantes genéticas não são necessárias nem suficientes para causar determinadas doenças.

${ }^{3}$ No final do século XX, a genética molecular se preocupou, sobretudo, com a inter-relação entre as macromoléculas de DNA (ácido desoxirribonucléico), e como essas moléculas sintetizam os polipeptídios, os componentes básicos de todas as proteínas. Só nos últimos anos a atenção se voltou para as diversas atividades críticas do RNA, que não estão diretamente envolvidas com a produção de proteína.

${ }^{4}$ A importância da regulação genética foi observada a primeira vez por Jacob e Monod, há mais de 40 anos (1961), mas foi dada prioridade ao mapeamento da estrutura do DNA.

${ }^{5}$ A associação entre os baixos níveis de educação e o maior risco de DA tardia é largamente aceita como essencial, embora essa hipótese não influencie os achados do Nun's Study (SNOWDON, 2001).

${ }^{6}$ A maior parte da pesquisa atual em epigenética enfoca a expressão e a regulação dos genes, investigando as condições nas quais o gene é "ligado" ou "desligado". Questões afins, no nível fenotípico, indagam por que gêmeos monozigóticos nem sempre manifestam as mesmas doenças e, quando o fazem, a idade do começo pode diferir em até duas décadas (KCHMIEDESKAMP, 2004). Essa abordagem conceitualizada de modo restrito evidencia ainda mais as limitações do determinismo genético. Uma forma mais abrangente e crítica da epigenética, conhecida como "teoria dos sistemas de desenvolvimento" (DST), apoiada tanto por filósofos quanto por biólogos, vem ganhando terreno. Utilizando essa abordagem, argumenta-se que os fenômenos epigenéticos deveriam ser reconhecidos como independentes da variação genética. O ponto de partida é uma reviravolta ontológica do determinismo genético, e dá prioridade às interações dinâmicas dentre as muitas variáveis e com diversos desfechos possíveis. O biólogo Scott Gilbert argumenta que a abordagem da DST implica que "o nosso self se torna um self permeável. Cada um de nós é uma comunidade complexa; na verdade, uma coleção de ecossistemas" (GILBERT, 2002, p. 213). No nível biológico surge a questão fundamental sobre se o gene, 
definido como uma seqüência da DNA, pode contar como a unidade da hereditariedade, sobretudo [tendo-se em vista] como a pesquisa recente sugere [fortemente] que os fenômenos epigenéticos podem ser transmitidos de uma geração a outra (CHAMPAGNE e MEANEY, 2001).

${ }^{7} \mathrm{Um}$ dos principais pesquisadores do projeto REVEAL me pediu para desenvolver a parte qualitativa da pesquisa, após as entrevistas iniciais estarem quase completas. Expressei minhas reservas quanto ao projeto, mas concordei em participar dele, considerando que iria entrevistar os médicos e os conselheiros em genética envolvidos, além de uma amostra de indivíduos selecionados. Três alunos de pós-graduação, Janalyn Prest, Stephanie Lloyd e Heather Lindstrom, participaram da concepção dos protocolos de entrevista e realizaram a maior parte das entrevistas com os sujeitos da pesquisa. 


\section{ABSTRACT}

\section{The Molecularized Mind and the Search for Incipient Dementia}

The author presents a critique of the prevailing genetic determinism in part of the genetic research, based on a revision of its main historical landmarks, resorting to the works of authors such as Kay and Lewontin, among others. Building on this delimitation, she examines the discussions on the possibility of an early diagnosis of Alzheimer's Disease (AD), including attempts to identify possible risk markers for it, including the discussion of the very diagnostic and taxonomic difficulties of DA, in particular of the termed late onset form. The author emphasizes the extent that current causal theories (relevant to the idea of early diagnosis) downplay or even omit the role of social factors in the onset of AD. She then outlines the diverse and conflicting findings on possible genetic risk markers for $\mathrm{AD}$, which, even with meager results, still lead to the production of tests for their detection. Finally, the author examines in detail the REVEAL project, of the National Institutes of Health (NIH), currently under way, which aims to identify the APOE gen in the general American population. The article concludes with a description of the subjective repercussions in the subjects that participated in that test.

Key words: Alzheimer's Disease; Medical Anthropology; genetics; science studies. 